\title{
Prenatal Zidovudine Treatment Modifies Early Development of Rat Osteoid - Confocal Microspectroscopy Analysis
}

\author{
Zofia Drzazga $^{1}$ (D) $\cdot$ Wojciech Ciszek ${ }^{1} \cdot$ Mariusz Binek ${ }^{1}$
}

Received: 19 June 2019 / Accepted: 27 August 2019/Published online: 16 October 2019

(C) The Author(s) 2019

\begin{abstract}
Autofluorescence of the bone extracellular matrix (ECM) has not been widely explored although the ECM plays a very important role in bone development. In our research we focused on examining the bone matrix of very young animals due to the intense growth process during the first month of life. Structure images and fluorescence spectra of the bone surface were carried out using confocal fluorescence microscope Eclipse Ti-S inverted CLSM (NIKON, Japan) for compact tibia of healthy 7-, 14- and 28-dayold rat newborns after prenatal zidovudine administration in comparison with control. Spectral features of ECM autofluorescence were analyzed statistically by taking into consideration $p<0.05$. The CLSM technique allows for simultaneous examination of the structure and autofluorescence from selected areas of the bone surface. Excessive autofluorescence of ECM after prenatal zidovudine administration influences bone growth incommensurably to the newborns' age. Therefore the possibility of an additional non-enzymatic mechanism of collagen cross-linking in the first two weeks of life of newborn rats prenatally treated with zidovudine has been considered. Our results suggest that ECM autofluorescence can be an indicator of bone development in the normal and pathological state.
\end{abstract}

Keywords ECM $\cdot$ Collagen cross-links $\cdot$ Newborn rats $\cdot$ Zidovudine $\cdot$ Fluorescence confocal laser scanning microscopy

\section{Introduction}

Bone is a complex tissue whose proper functioning is based on cooperation between living cells (osteoblasts, osteoclasts, and osteocytes) and extracellular matrix (ECM) composed of organic matter dominated by collagen proteins and the inorganic component consisting mainly of hydroxyapatite. Nowadays anatomy and physiology of bone system and its cells are well described. Recently normal osteogenesis and bone development during whole human or mammalian life as well as mechanisms of disorders detected in bone physiology and bone growth have been researched by many authors, i.e. [1-6].

Our earlier work on bone focused on studies of the effect of antiretroviral drugs, such as zidovudine or indinavir, that are

Zofia Drzazga

zofia.k.drzazga@gmail.com; zofia.drzazga@us.edu.pl

1 Department of Medical Physics, A. Chełkowski Institute of Physics, University of Silesia, ul. 75 Pułku Piechoty 1A,

41-500 Chorzów, Poland used among others to treat the HIV infections, on bone tissue development in an animal model [7-9]. It was shown using the XRF technique that maternal administration of indinavir disturbs concentration of elements of inorganic matter, especially in trace elements such as zinc and strontium whose content changes regulate the Ca level. On the other hand, prenatal zidovudine treatment influenced organic matter to a greater extent, which we revealed by using laser fiber spectroscopy. However, it is interesting to deepen investigation of ECM using confocal laser scanning microscope with the option of obtaining spectra from a specific microscopic area.

Advanced microscopic techniques including multi-photon microscopy are often applied in characterization of biological tissues including bone in biomedical research of oncological as well as non-oncological cases associated with environmental stress, genetic manipulation and drug treatment [10-13]. CLSM has been an effective tool for investigating bone calcification [14] as well as the cells embedded within the mineralized bone matrix. Bone-resorbing osteoclasts can be analyzed by confocal microscopy [15]. Combined CLSM and Differential Interference Contrast (DIC) microscopy methods were used for histotomography and 3D imaging of the structure and processes of osteocytes [16]. Non-destructive 
complementary imaging of cancellous bone contributed to the understanding of its bimodal structure, which is important for the development of tissue engineering. Analyzes of confocal images of microcracks in relation to biomechanical properties of ageing human cortical bone were also reported [17].

This paper presents the usefulness of confocal fluorescence microscopy for testing the physiological development of the bone matrix in the first month of life and the potentially negative effect of prenatal treatment with zidovudine. For this purpose, confocal images have been analyzed to reveal changes caused by the anti-HIV treatment in patterns of extracellular matrix of developing bones. Moreover, we found it worthwhile to check if autofluorescence of ECM could be a marker of bone development in the normal as well as pathological state.

\section{Material and Methods}

The bones of newborn rats in three age groups (7-, 14- and 28day-old) received from Department of Pharmacology at the Medical University of Silesia were used for this study. The section of the rats was performed with the approval of The Local Ethics Committee for Animal Experiments in Katowice (no. 9/2008) according to the Helsinki Declaration in the framework of the grant No.2POD08530 of the Polish Ministry of Education and Science. The preparation process of bone samples was described previously [7]. Tibias from rat offspring whose mothers were administered with $0.9 \% \mathrm{NaCl}$ were compared to newborns' bones whose mothers received antiretroviral agent zidovudine at a $200 \mathrm{mg} / \mathrm{kg}$ [9]. Such a dose was chosen on the basis of earlier reports [e.g. 18] as well as our own experience, which indicated increasing mortality of rat fetuses at higher doses. Zidovudine ZDV (aka. azidothymidine) was one of the first medications used in antiretroviral therapy (ARV) as a representative of NRTIs blocking the process of replication in infected cells $[19,20]$. Unfortunately, genotoxic effects of such therapies were observed, including negative influence on bone tissue [21, 22]. Hence study of bones from very young rats (less than one month) is important due to the intense growth process in this stage of development.

Measurements were performed for equinumerous groups of bones (6 tibias each) from younger newborns 7- and 14day-old after maternal treatment with zidovudine and control, $7 Z, 14 Z, 7 C$ and $14 C$, respectively. For 28 -day-old rats only 4 tibias were measured in both control $28 \mathrm{C}$ and zidovudine $28 \mathrm{Z}$ groups. The control groups are presumed to be healthy groups of rats' tibias, where bone development is physiologically normal.

All samples were studied using Eclipse Ti-S inverted CLSM (NIKON, Japan). The images of bone surface were registered using 20x objective lens (NA 0.45) giving final zoom equal to 200x. To provide the best visibility the confocal plane was set on the flattest surface of the sample. As an excitation source for autofluorescence study, $404 \mathrm{~nm}$ laser diode (Melles Griot, $<500 \mathrm{~mW}$ ) was used because such excitation wavelength was found to produce the highest contrast in detecting early lesions $[10,23]$. Emission signal was detected by the photomultiplier (PMT) with spectral resolution set at $5 \mathrm{~nm}$ in the range of 400-700 nm. Autofluorescence spectra were collected from images of compact bone surface near diaphysis focusing on intercellular substance of bone where circular ROIs (diameter $20 \pm 5 \mu \mathrm{m}$ ) were assigned within confocal plane to reduce the noise of emission signal (5-6 ROIs in each sample). Background spectrum including laser beam spectrum and PMT noise was also recorded.

All spectral measurements were formulated using Origin (OriginLab, USA) software. Originally recorded fluorescence spectra from tibia of newborns rats were normalized to the maximum of excitation peak in measured tissue and then the background signal was subtracted. Moreover, spectra were normalized to average intensity calculated in the 650 $700 \mathrm{~nm}$ range for all spectra. Such a procedure was used earlier by Mayinger et al. [24] as optimal for investigation of biological samples whose emission signal depends on the illumination and the position of the probe. This method takes into account data averaging, normalization and subtraction. This allows us to compare the fluorescence plots and to reveal substantial differences between registered spectra.

Statistical analysis was performed using STATISTICA12 software (StatSoft, USA). Obtained results of measurements were processed to eliminate outliers (Grubbs test). Results were distributed normally according to the normality tests (Kolmogorov-Smirnov). In the statistical calculations the standard level of confidence was assumed to be $p=0.05$ for ANOVA tests to estimate the presence of statistical differences amongst analyzed groups.

\section{Results}

\section{Confocal Fluorescence Microscopy Imaging}

Representative images of age-related development of compact bone surface architecture within diaphysis of tibia are presented in Fig. 1. In fact, they reveal organic extracellular matrix (ECM, osteoid), composed mostly of type I collagen that gradually mineralizes to form mature bone. Collagen fibrins are the most fluorescent matter observed in the confocal plane contrasting with black areas which probably originate from the blood vessel canals (Volkmann's canals supplying nutritional ingredients necessary for bone development) as well numerous lacunae visible in particular in the tibia of the youngest newborns. 


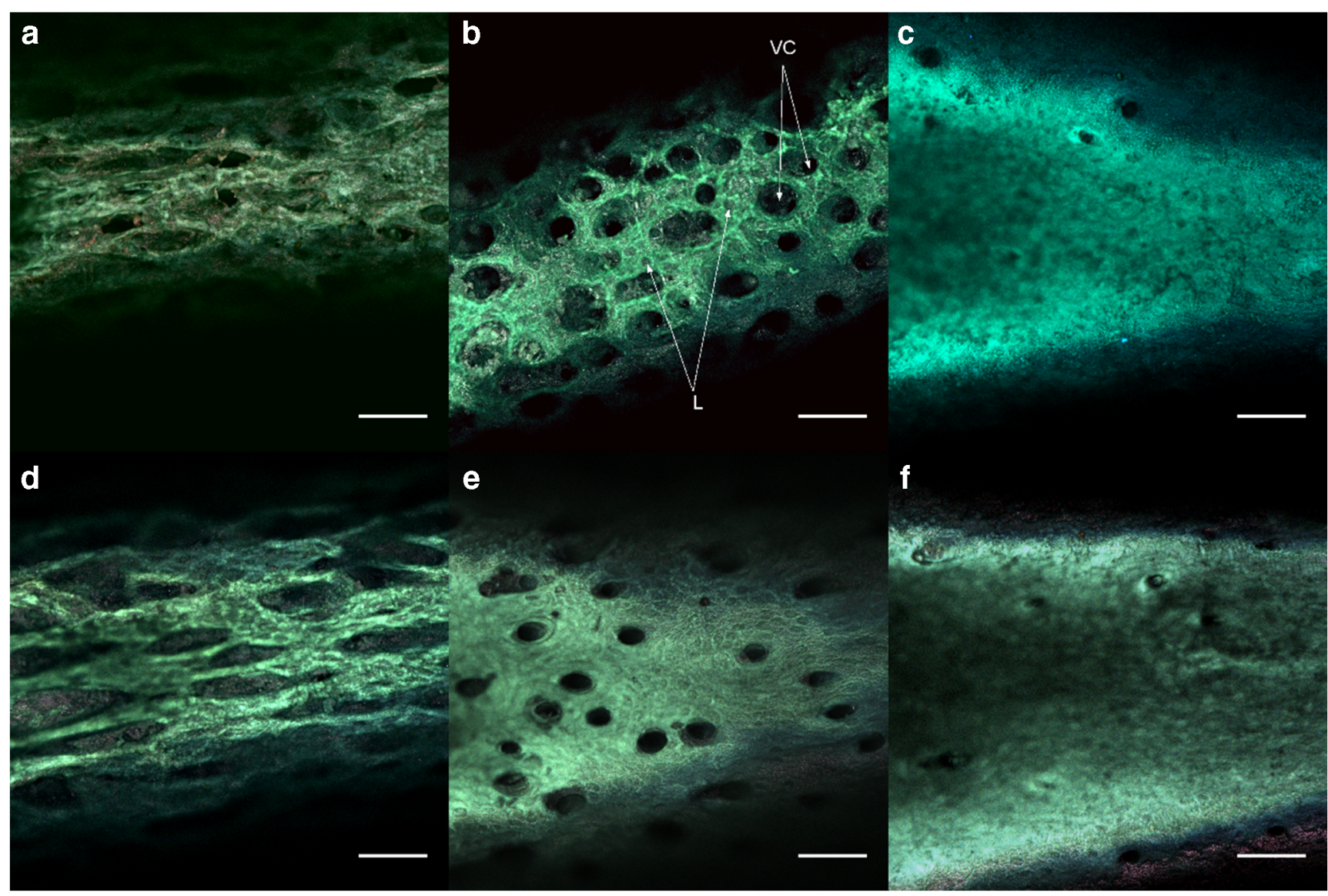

Fig. 1 Representative age relative images of the tibia diaphysis surface of control newborn rats: $\mathbf{a}-7 \mathrm{C}, \mathbf{b}-14 \mathrm{C}$, $\mathbf{c}-28 \mathrm{C}$, and prenatal zidovudine treated newborns: d - 7Z, e - 14Z, f - 28Z. In picture B) the Volkamnn's channels VC and lacunae L are marked. Zoom 200x, scale bar: $100 \mu \mathrm{m}$

Images registered by our microscope show eye-catching differences in size, architecture and distribution of histological elements between the studied bone groups. To assure description clarity control and zidovudine groups are considered separately.

Imaging revealed fragile structure of ECM in the $7 C$ group what is presented in Fig. 1a. Bone surface shows an irregular and spongy architecture with supramolecular structure of collagen fibrils suggesting a presence of trabecular meshwork at the beginning of bone development. Fig. $1 \mathrm{~b}$ displays bone matrix patterning in 14-day-old rat bone (14C), altered a little due to increasing of collagen cross-linking and progressive bone mineralization. Further mineralization of proteinaceous matrix leads to the formation of dense cortical bone. Surface of the tibia from the $28 \mathrm{C}$ group (Fig. 1c) demonstrates an almost mature compact bone as a result of matrix conformation from woven to lamellar bone and the process of mineralization.

Process of bone development during the first month of life of rat newborns prenatally treated with zidovudine is presented in Fig. 1d - f. Tibia of 7-day-old newborns (7Z) also show a spongy structure but self-assembly of collagen molecules into collagen fibers seems to be more advanced than in the control group (see Fig. 1d vs. a). The distinct differences in the pattern of collagen forming osteoid are observed in bones of 14-dayold newborns. Circularity of Volkmann's canals is still noticeable but the collagen fibrils are clustered in parallel or concentric arrays characteristic for lamellar bone [1, 2]. Nevertheless, it should be noted that tibias of zidovidine groups are markedly bigger than the control ones in each age group.

\section{Autofluorescence Spectra}

Autofluorescence spectra of the bone organic ECM measured in our experiment are presented in Fig. 2. As hydroxyapatitelike compounds are not fluorescent so the presence of it could be omitted. The characteristic broad band of emission with peak at about $480 \mathrm{~nm}$ is observed; apparent side band on part of longer wavelengths is found in all studied samples. Such a signal is similar to fluorescence spectra of biological tissues obtained by fiber laser spectroscopy described by various researchers earlier [9, 23, 24]. Autofluorescence in our experiment is attributed to closely spaced overlapping emissions generated by a number fluorescent compounds such as: collagen, $\mathrm{NAD}(\mathrm{P}) \mathrm{H}$, flavins, fatty acids, vitamins and lipofuscins see literature [25]. 
a

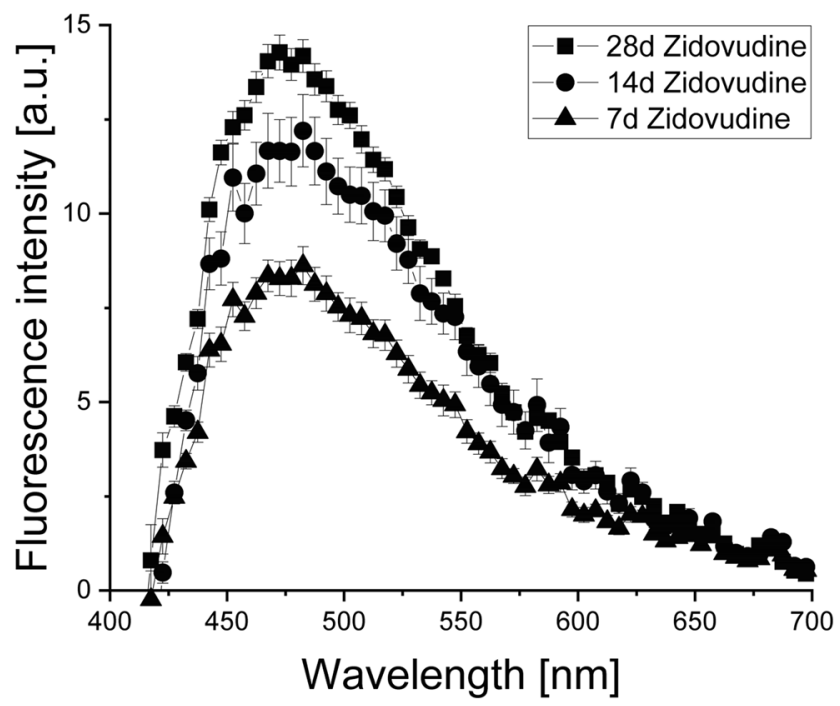

b

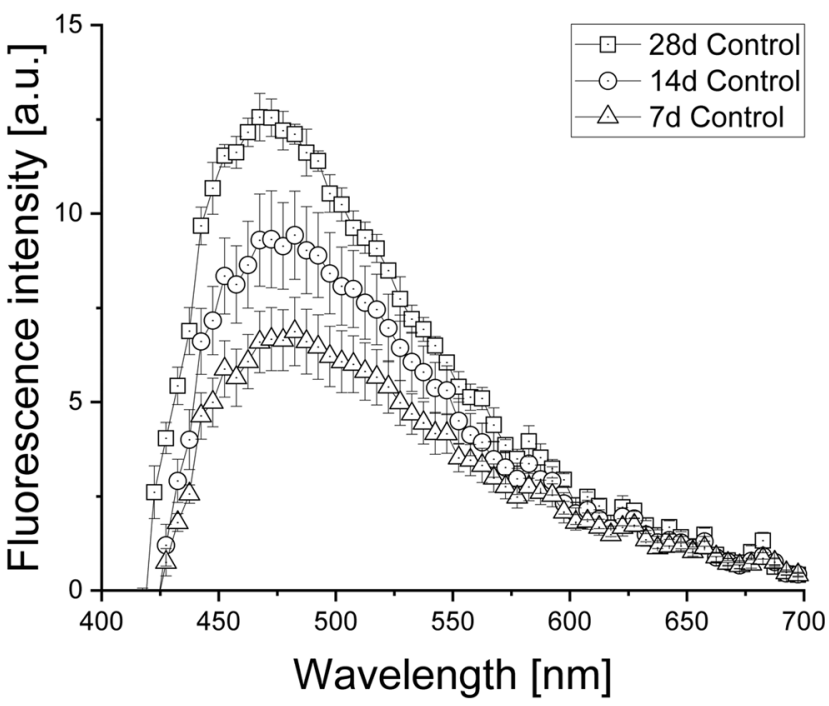

Fig. 2 Average autofluorescence spectra of bone extracellular matrix from maternal zidovudine treatment group (a) and control (b) as a function of age (d - day-old) under $404 \mathrm{~nm}$ laser excitation

Emission spectra (shown in Fig. 2) disclose similar shape in all groups but the intensity of fluorescence depends on drug and age of newborns. Fluorescence normally increases with the age of newborn rats, but prenatal zidovudine drug delivery enhances the signal. The mentioned increase in the zidovudine group seems to be actually dependent on both ageing and drug administration processes but in different way. Therefore for better insight into the problem we analyzed: fluorescence intensity, peak position and difference in maximum between the studied groups. These basic spectral parameters allowed for a fuller description of phenomena during our study - they are listed in Table 1. For 7- and 14-day-old groups maximum peaks are located at $482.5 \mathrm{~nm}$, while for the $28 \mathrm{C}$ and $28 \mathrm{Z}$ groups a blueshift of maximum appears: at $15 \mathrm{~nm}$ and $10 \mathrm{~nm}$, respectively.

Analysis of the variation of emission intensity indicates statistically significant differences $(p<0.001)$ regards age for the control bones as well as for the zidovudine group. However, no significant differences are found for groups between $14 \mathrm{C}$ and $7 \mathrm{Z}$ as well as between $14 \mathrm{Z}$ and $28 \mathrm{C}$. This means that the fluorescence of bones of older rats from the control group is close to the emission of bones of younger rats from the zidovudine group. Age-dependent development rate of osteoid is estimated as a mathematical intensity subtraction $\Delta_{\text {intensity }}$ (Table 1). During the first 2 weeks of rats' life prenatal drug administration causes faster increase of fluorescence peak intensity compared with the increase observed in the control group. However, a different effect in $\Delta_{\text {intensity }}$ was found for the next life period, between the fourth and second week of life $(28 \mathrm{~d}-14 \mathrm{~d})$. The difference in fluorescence peak intensity is smaller in the zidovudine group than in the control group unlike the first two weeks of rats' lives. Hence at the end of the experiment taking into account the difference between the last and first week of rats' life $(28 d-7 d)$ - a suppression of fluorescence intensity increase between zidovudine and control groups was observed.

Mechanisms of bone development can be better understood by using the normalized differential spectra of osteoid autofluorescence. Emission differences between the zidovudine group and the control group for different age of newborns is displayed in Fig. 3.
Table 1 Mean intensity of osteoid fluorescence in maximum emission peak as a function of rat's newborns age for control group compared with zidovudine group and intensity difference for successive age groups $(\mathrm{C}-$ control group, $\mathrm{Z}$ - zidovudine group, $\mathrm{d}$ - day-old)

\begin{tabular}{|c|c|c|c|c|c|}
\hline \multirow[t]{2}{*}{ Group } & \multicolumn{2}{|l|}{ Parameters } & \multicolumn{3}{|c|}{$\begin{array}{l}\text { Intensity difference between age } \\
\text { groups } \Delta_{\text {intensity }}\end{array}$} \\
\hline & Maximum emission $\lambda_{\max }[\mathrm{nm}]$ & Maximum intensity $\mathrm{I}_{\max }$ [a.u.] & $14 d-7 d$ & $28 d-14 d$ & $28 \mathrm{~d}-7 \mathrm{~d}$ \\
\hline $7 \mathrm{C}$ & $482.5 \pm 2.5$ & $6.87 \pm 0.91$ & & & \\
\hline $14 \mathrm{C}$ & $482.5 \pm 2.5$ & $9.43 \pm 1.17$ & 2.56 & & \\
\hline $28 \mathrm{C}$ & $467.5 \pm 2.5$ & $12.56 \pm 0.63$ & & 3.13 & 5.69 \\
\hline $7 Z$ & $482.5 \pm 2.5$ & $8.63 \pm 0.51$ & & & \\
\hline $14 Z$ & $482.5 \pm 2.5$ & $12.20 \pm 0.96$ & 3.57 & & \\
\hline $28 \mathrm{Z}$ & $472.5 \pm 2.5$ & $14.28 \pm 0.46$ & & 2.08 & 5.65 \\
\hline
\end{tabular}




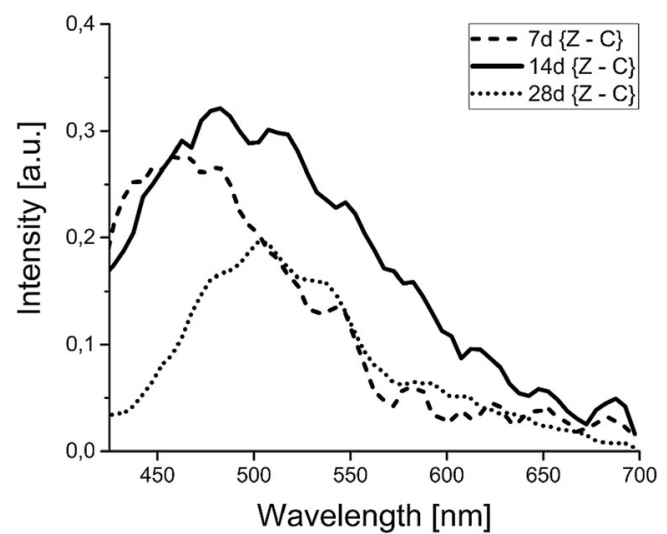

Fig. 3 Differential plots of osteoid emission normalized to control, obtained for tibia taken from newborns after maternal treatment with zidovudine and control in all studied age groups ( $\mathrm{Z}$ - zidovudine group, C- control)

The largest excessive signal is found in bones from 14-dayold rats. The line shape reveals many component perturbations occurring through the range of the studied wave lengths. Broad signal ( FWHM $=154 \pm 14 \mathrm{~nm}$ ) with maximum intensity (a.u.: $0,32 \pm 0,05$ ) located at about $482,5 \mathrm{~nm}$ singles out this group from among others. For 7-day-old rats a strong blueshift maximum about $25 \mathrm{~nm}$ in respect to the 14-day-old group is noticeable. Differential plot of autofluorescence of tibia taken from 28-day-old rats shows the smallest excessive signal (FWHM $=96 \pm 8 \mathrm{~nm}$ ) among the studied age groups but is shifted towards red with respect to the group of 14 day old rats - located near 502,5 nm. It follows from our analysis that contributions of different endogenic fluorophores change at a varying degree with rat age.

\section{Discussion}

In our study we focused on monitoring the development of bone matrix in newborn rats using confocal fluorescence microspectroscopy which allows to investigate selected tissue on microscopy level. The differentiated patterning of bone matrix from an initial trabecular meshwork towards dense cortical bone dependent on status bone tissue could be observed (Fig. 1). As expected, the obtained confocal images confirm that organic extracellular matrix is dominated by collagen fibrils which constitute ca. $85 \%$ of bone ECM [1]. Important aspects of alternations in bone extracellular matrix during the first month of rat newborns life are reflected in the autofluorescence measurements. It should be noted that progressive mineralization does not reduce collagen emission, as previously mentioned [26]. It is noteworthy that age and drug related changes in autofluorescence spectra of newborn rats' bone matrix on microscope level are in a good quality agreement with results obtained from $1,8 \mathrm{~mm}$ diameter circular areas of compact bone by fiber laser spectroscopy $[7,9]$ for younger newborns.

An age-increasing autofluorescence of bone matrix seems to be primarily associated with the increasing number of fluorescent molecules, mainly of collagen ones emitting in the range 400-510 nm [25]. However, our preliminary study of autofluorescence of the surface of the compact bone by steady fluorescence spectroscopy [9] suggested essential contributions generated not only by collagen but also by nicotinamide adenine dinucleotide $(\mathrm{NAD}(\mathrm{P}) \mathrm{H})$ in the visible range of wavelengths. Basing on autofluorescence under excitation of $404 \mathrm{~nm}$ obtained in this framework, it is difficult to precisely determine collagen and $\mathrm{NAD}(\mathrm{P}) \mathrm{H}$ contributions due to their overlapping emissions. In addition, the fluorescence contributions may not be additive due to complicated interactions of the fluorophores with the molecular environment. Detail analyses of collagen and $(\mathrm{NAD}(\mathrm{P}) \mathrm{H})$, as two of the major tissue fluorescent biomarkers of pre- and cancerous changes were performed using Monte Carlo technique [27], chemometric tools [28] and MCR-ALS method [29].

Bone matrix is mostly composed of collagenous proteins but non-collagenous proteins (10 to 15\% of total bone protein) including proteoglycans, glycosylated proteins, gammacarboxylated (gla) proteins and 2HS-glycoprotein may affect bone cell activity and regulate bone mineral deposition [1] The most prevalent non-collagenous protein - osteonectin, (approximately $2 \%$ of total protein in developing bone) is thought to affect osteoblast growth and matrix maturation regulating fibril diameter. On the other hand, calcium- and phosphate-binding proteins such as osteocalcin, osteopontin, bone sialoprotein and alkaline phosphatase participate in matrix mineralization by regulating the amount and size of hydroxyapatite crystals formed. Such an imposition of mentioned tissue processes must be taken into account during studies when prenatal treatment with antiretroviral drugs is used. It is clear that therapy in pregnancy affects the development of young bone, especially altering the activity of osteoid proteins and coenzymes. It was reported that the activity of zidovudine as a nucleoside analogue which competes with natural metabolites for an active place in enzymes may disturb their functions [19, 30].

The effect of maternal therapy with zidovudine on bone tissue formation revealed in our studies the increase of ECM emission which is in opposition to fluorescence decrease in malignant bone cells [23]. Unfortunately, in our work similar trends in ECM autofluorescence changes with respect to age and prenatal pathology (Fig. 2, Table 1) make this analysis difficult. Only normalized differential spectra enabled specification of bone tissue in relation to newborns prenatally treated with zidovudine. Spectral profiles of differential plots of bone ECM (Fig. 3) point to the age dependent excess of emission with the shifting of the maximum towards the shorter wavelengths for the younger rats in comparison with the oldest 
ones. Such behavior of the differential spectrum can be associated with the different degree of maturation of collagen fibers stimulated by altering protein growth factors as well as by possible changes in fluorescence signals of metabolic enzymes ratios, like $\mathrm{NAD}(\mathrm{P}) \mathrm{H}_{\text {bound/free, }}$, and $\mathrm{NAD}(\mathrm{P}) \mathrm{H}_{\text {total/oxi- }}$ dized flavins on which the spectral shape can depend, as discussed in [25].

It was presented by Bailey et al. [31] that collagen crosslinking involves two different mechanisms, one enzymatically controlled cross-linking during development and maturation and the other an adventitious non-enzyme mechanism following maturation of the tissue. Advanced glycation end products (AGEs) are thought to be the major cause of the dysfunction of collagenous tissues in ageing, osteoporosis, diabetes [32] as well in cardiovascular diseases [33]. It is not excluded that an additional nonenzymatic cross-linking may have pathophysiological implications in bone ECM of rat newborns with maternal administrated zidovudine, especially during the first two weeks of rat' life. Too rapid, non-adequate to age increase of collagen cross-linkage could be interpreted as a premature process of ageing of collagenous tissue during bone development. Taking into consideration the maximum fluorescence of AGEs about 440-450 nm occurring in biological substances, it seems likely that the abnormal increase in intensity blue-shifted fluorescence part of differential spectra is due to the additional emission of AGEs deposits in bone ECM of younger newborn rats, especially 7-day old ones. Differential spectrum of 14-day old rats is additionally influenced by fluorescence contribution covering the yellow-reddish region in which lipofuscins or lipofuscin-like lipopigments may emit (480-700 nm) [25]. The presence of these fluorophores might be a marker of the side effect of maternal treatment with drug on development of the bone matrix. Earlier physiological intracellular accumulation of lipofuscins in the central nervous system with ageing as well as in response to pathological conditions or to toxic compounds were reported [34]. Autofluorescence of lipofuscin in retinal pigment epithelium due to Stargardt's disease and age-related macular degeneration $[35,36]$ was also discussed. In addition, even a small amount of lipids in the mineralized bone tissue [37] taking part in bone physiology in relation to their metabolism may influence the differential spectra (Fig. 3) at about 470-480 nm.

A reduction of side effects of prenatal drug administration was observed in the tibia of the oldest rats tested. It is noteworthy that excessive contributions at the beginning and at the end of the differentiated spectra disappear for tibia of the 28 day-old rats which might indicate a return to basic enzymatic cross-linking.

\section{Conclusions}

Our investigations show applicability of confocal laser scanning microscopy for comprehensive characterization of organic extracellular matrix and its mineralization in the first month of life of rat newborns. Changes in the pattern of collagen forming the osteoid and differences in the emission of ECM fluorophores allow to monitor bone development in the normal and disturbed state due to prenatally administration of anti-HIV drug zidovudine. The possibility of an additional non-enzymatic mechanism of collagen cross-linking in the first two weeks of life of newborn rats is considered. ECM autofluorescence can be an indicator of bone development and hence may be useful in clinical trials.

Acknowledgements This study was supported by statutory funds of University of Silesia.

\section{Compliance with Ethical Standards}

Conflict of Interest All authors have no conflict of interests.

Ethical Standards All procedures performed in studies involving animals were in accordance with the ethical standards of the institutional review board and/or national research committee, and with the 1964 Helsinki Declaration and its later amendments or comparable ethical standards. The study protocol was approved by Local Ethics Committee for Animal Experiments in Katowice (9/2008) in the framework of the grant No.2POD08530 of Polish Ministry of Education and Science (Z. Drzazga).

Open Access This article is distributed under the terms of the Creative Commons Attribution 4.0 International License (http:// creativecommons.org/licenses/by/4.0/), which permits unrestricted use, distribution, and reproduction in any medium, provided you give appropriate credit to the original author(s) and the source, provide a link to the Creative Commons license, and indicate if changes were made.

\section{References}

1. Kini U, Nandeesh BN (2012) Physiology of bone formation remodeling, and metabolism. In: Fogelman I et al (eds) Radionuclide and hybrid bone imaging. Springer-Verlag, Berlin Heidelberg. https:// doi.org/10.1007/978-3-642-02400-9-2

2. Shapiro F (2008) Bone development and its relation to fracture repair. The role of mesenchymal osteoblasts and surface osteoblasts. Eur Cell Mater 15:53-76. https://doi.org/10.22203/eCM. v015a05

3. Paschalis EP, Shane E, Lyritis G, Skarantavos G, Mendelsohn R, Boskey AL (2004) Bone fragility and collagen cross-links. J Bone Miner Res 19(12):2000-2004

4. Kowada T, Kikuta J, Kubo A, Ishii M, Maeda H, Mizukami S, Kikuchi K (2011) In vivo fluorescence imaging of bone-resorbing osteoclasts. J Am Chem Soc 133:17772-17776. https://doi.org/10. $1021 /$ ja2064582 
5. Saito M, Marumo K (2010) Collagen cross-links as a determinant of bone quality: a possible explanation for bone fragility in aging, osteoporosis, and diabetes mellitus. Osteoporos Int 21(2):195-214. https://doi.org/10.1007/s00198-009-1066-z

6. Nishikawa T, Kokubu M, Kato H, Imai K, Tanaka A (2012) Confocal laser scanning microscopy in study of bone calcification. Appl Surf Sc 262:64-68

7. Drzazga ZK, Michalik K, Kaszuba M, Nowińska B, Trzeciak H (2010) Optical and X-ray fluorescence spectroscopy studies of bone and teeth in newborn rats after maternal treatment with Indinavir. Photochem Photobiol 86:87-95. https://doi.org/10.1111/j.17511097.2009.00632.x

8. Maciejewska K, Drzazga ZK, Kaszuba M (2015) The changes in bone organic and inorganic matrix in newborn rats after maternal application of antiretroviral agents: Indinavir and zidovudine. BioFactors 41(3): 198-208

9. Drzazga ZK, Maciejewska K, Michalik K, Kaszuba M, Nowińska B (2011) Does maternal treatment with zidovudine affect changes in mandibles of newborns? Laser induced fluorescence study. J Fluoresc 21(3):883-886

10. Francisco ALN, Correr WR, Azevedo LH, Kern VG, Pinto CAL, Kowalski LP, Kurachi C (2014) Fluorescence spectroscopy for the detection of potentially malignant disorders and squamous cell carcinoma of the oral cavity. Photodiagn Photodyn Ther 11(2):82-90

11. Gabrecht T, Andrejevic-Blant S, Wagnières G (2007) V. Blue excited autofluorescence spectroscopy and imaging of normal and cancerous human bronchial tissue after formalin fixation. Photochem Photobiol 83(2):450-459

12. Palczewska G, Dong Z, Golczak M, Hunter JJ, Williams DR, Alexander NS, Palczewski K (2014) Noninvasive two-photon microscopy imaging of mouse retina and retinal pigment epithelium through the pupil of the eye. Nat Med 20(7):785-789

13. Zhang J, Kiser PD, Badiee M, Palczewska G, Dong Z, Golczak M, Palczewski K (2015) Molecular pharmacodynamics of emixustat in protection against retinal degeneration. J Clin Invest 125(7):27812794

14. Nesbitt SA, Horton MA (1997) Trafficking of matrix collagens through bone-resorbing osteoclasts. Science 276(5310):266-269. https://doi.org/10.1126/science.276.5310.266

15. Kamioka H, Honjo T, Takano-Yamamoto T (2001) A threedimensional distribution of osteocyte processes revealed by the combination of confocal laser scanning microscopy and differential interference contrast microscopy. Bone. 28(2):145-149

16. Smith IO, Ren F, Baumann MJ, Case ED (2006) Confocal laser scanning microscopy as a tool for imaging cancellous bone. J Biomed Mater Res B: Appl Biomat 79(1):185-192

17. Zioupos $P$ (2000) Accumulation of in-vivo fatigue microdamage and its relation to biomechanical properties in ageing human cortical bone. J Microsc 201:270-278

18. Mamede JAV, Simoes MDJ, Novo NF, Juliano Y, Oliveira-Filho RM, Kulay L Jr (1995) Chronic effects of azidothymidine and acyclovir on pregnant rats. Gen Pharmacol 26:523-526

19. Hoffman RM, Landovitz RJ (2004) Complications of antiretroviral therapy for HIV: mechanisms of action, NRTIs, and NNRTIs. J Infect Dis 9(2):2-11

20. Olivero OA, Parikka R, Poirier MC, Vähäkangas K (1999) 3'-azido-3'-deoxythymidine (AZT) transplacental perfusion kinetics and DNA incorporation in normal human placentas perfused with AZT. Mutat Res 428:41-47
21. McComsey GA, Tebas P, Shane E, Yin MT, Overton ET, Huang JS, Aldrovandi GM, Cardoso SW, Santana JL, Brown TT (2010) Bone disease in HIV infection: a practical review and recommendations for HIV care providers. Clin Infect Dis 51(8):937-946

22. Maccabruni A, Pedrotti L, Lazzaroni C, Mora R, Quaglini S (2006) Study on changes in bone metabolism in a cohort of HIV-infected pregnant women and their uninfected children. Miner Bone Metab 3:88-91

23. Khosroshahi ME, Rahmani M (2012) Detection and evaluation of normal and malignant cells using laser-induced fluorescence spectroscopy. J Fluoresc 22(1):281-288

24. Mayinger B, Horner P, Jordan M, Gerlach C, Horbach T, Hohenberger W, Hahn EG (2000) Light-induced autofluorescence spectroscopy for tissue diagnosis of GI lesions. Gastrointest Endosc 52(3):395-400

25. Croce AC, Bottiroli G (2014) Autofluorescence spectroscopy and imaging: a tool for biomedical research and diagnosis. Eur J Histochem 58(4):320-337

26. Prentice AID (1967) Autofluorescence of bone tissues. J Clin Pathol 20:717-719

27. Drezek R, Sokolov K, Utzinger U, Boiko I, Malpica A, Follen M, Richards-Kortum R (2001) Understanding the contributions of NADH and collagen to cervical tissue fluorescence spectra: modeling, measurements, and implications. J Biomed Opt 6(4):385-396

28. Georgakoundi I et al (2002) NAD(P)H and collagen as in vivo quantitative fluorescence biomarkers of epithelial precancerous changes. Cancer Res 62:682-687

29. Pu Y, Wang W, Tang G, Alfano RR (2010) Changes of collagen and nicotinamide adenine dinucleotide in human cancerous and normal prostate tissues studied using native fluorescence spectroscopy with selective excitation wavelength. J Biomed Opt 15(4):047008

30. Villa A, Guerrini MM, Cassani B, Pangrazio A, Sobacchi C (2009) Infantile malignant, autosomal recessive osteopetrosis: the rich and the poor. Calcif Tissue Int 84:1-12

31. Bailey AJ, Paul RG, Knott L (1998) Mechanisms of maturation and ageing of collagen. Mech Ageing Dev 106(1-2):1-56

32. Yamamoto M, Sugimoto T (2016) Advanced glycation end products, diabetes and bone strength. Curr Osteoporos Rep 14(6):320 326. https://doi.org/10.1007/s11914-016-0332-1

33. Raposeiras-Roubín S, Rodiño-Janeiro BK, Paradela-Dobarro B et al (2013) Fluorescent advanced glycation end products and their soluble receptor: the birth of new plasmatic biomarkers for risk stratification of acute coronary syndrome. PLoS One 8(9):e74302. https://doi.org/10.1371/journal.pone.0074302

34. Patková J, Vojtíšek M, Tůma J, Vožeh F, Knotková J, Santorová P et al (2012) Evaluation of lipofuscin-like pigments as an index of lead-induced oxidative damage in the brain. Exp Toxicol Pathol 64: $51-56$

35. Kennedy CJ, Rakoczy PE, Constable IJ (1995) Lipofuscin of the retinal pigment epithelium: a review. Eye 9:763-771

36. Nandakumar N, Buzney S, Weiter JJ (2012) Lipofuscin and the principles of fundus autofluorescence: a review. Semin Ophthalmol 27:197-201

37. During A, Penel G, Hardouin P (2015) Understanding the local actions of lipids in bone physiology. Prog Lipid Res 59:126-146

Publisher's Note Springer Nature remains neutral with regard to jurisdictional claims in published maps and institutional affiliations. 